\title{
Nuclear waste viewed in a new light; a synchrotron study of uranium encapsulated in grout.
}

C. A. Stitt ${ }^{\mathrm{a}}$, M. Hart ${ }^{\mathrm{b}}$, N. J. Harker ${ }^{\mathrm{a}}$, K. Hallam ${ }^{\mathrm{a}}$, J. MacFarlane ${ }^{\mathrm{a}}$, A. Banos ${ }^{\mathrm{a}}$, C. Paraskevoulakos ${ }^{\mathrm{a}}$, E. Butcher ${ }^{\mathrm{c}}$, C. Padovani ${ }^{\mathrm{d}}$, T.B. Scott ${ }^{\mathrm{a}}$

${ }^{a}$ Interface Analysis Centre, H. H. Wills Physics Laboratory, University of Bristol, Tyndall Avenue, Bristol, BS8 1TL, United Kingdom.

${ }^{b}$ Diamond Light Source Ltd. Harwell Science and Innovation Campus, Fermi Avenue, Didcot, Oxfordshire OX11 0QX, United Kingdom.

${ }^{c}$ National Nuclear Laboratory, Seascale, Cumbria, CA20 1PG, United Kingdom.

${ }^{d}$ Radioactive Waste Management Limited (formerly the Radioactive Waste Management Directorate of the UK Nuclear Decommissioning Authority), Harwell, United Kingdom.

Email addresses: Camilla.stitt@ bristol.ac.uk, oxford.mike@gmail.com, nicholas.harker@esrf.fr, k.r.hallam@bris.ac.uk, james.macfarlane@bristol.ac.uk, antonis.banos@bristol.ac.uk,cp13846@bristol.ac.uk,ed.j.butcher@nnl.co.uk, cristiano.padovani@nda.gov.uk,t.b.scott@bristol.ac.uk

\begin{tabular}{|c|c|}
\hline Corresponding author: & $\begin{array}{l}\text { Dr Dr Thomas B Scott } \\
\text { Director } \\
\text { Interface Analysis Centre } \\
\text { University of Bristol, } \\
\text { H. H. Wills Physics Laboratory, } \\
\text { Tyndall Avenue } \\
\text { Bristol, UK, BS8 1TL } \\
\text { T +44 (0)117 } 331 \text { 1176 } \\
\text { F+44(0)117 925 5646 } \\
\text { t.b.scott@bristol.ac.uk }\end{array}$ \\
\hline
\end{tabular}




\section{Abstract}

How do you characterise the contents of a sealed nuclear waste package without breaking it open? This question is important when the contained corrosion products are potentially reactive with air and radioactive. Synchrotron $\mathrm{x}$-rays have been used to perform micro-scale in-situ observation and characterisation of uranium encapsulated in grout; a simulation for a typical intermediate level waste storage packet. X-ray tomography and $\mathrm{x}$-ray diffraction generated both qualitative and quantitative data from a grout encapsulated uranium sample before, and after, deliberately constrained $\mathrm{H}_{2}$ corrosion. Tomographic reconstructions provided a means of assessing the extent, rates and character of the corrosion reactions by comparing the relative densities between the materials and the volume of reaction products. The oxidation of uranium in grout was found to follow the anoxic $\mathrm{U}+\mathrm{H}_{2} \mathrm{O}$ oxidation regime, and the pore network within the grout was observed to influence the growth of uranium hydride sites across the metal surface. Powder diffraction analysis identified the corrosion products as $\mathrm{UO}_{2}$ and $\mathrm{UH}_{3}$, and permitted measurement of corrosion-induced strain. Together, $\mathrm{x}$-ray tomography and diffraction provide means of accurately determining the types and extent of uranium corrosion occurring, thereby offering a future tool for isolating and studying the reactions occurring in real full-scale waste package systems.

Key words: Uranium; Grout; Synchrotron X-ray tomography; X-ray Powder Diffraction; Uranium hydride. 


\subsection{Introduction}

Uranium metal originating from the reprocessing of spent Magnox nuclear fuel is a contributor to the UK's intermediate level waste (ILW) [1]. The uranium typically results from the carryover of metal attached to the Magnox cladding, which is removed from the spent fuel prior to reprocessing. Most ILW is currently encapsulated in grout contained within stainless steel canisters, ready for interim storage and eventually disposal. The safe long term containment of this ILW (in excess of 100 years) is an essential goal of the nuclear community and, accordingly, it is of critical importance to be able to evaluate or even directly monitor the corrosion state of the uranium-containing waste packages over long periods of time.

There are two primary concerns when considering the safe long term management of uranium-bearing ILW. Firstly, a potential safety challenge is posed by the production of pyrophoric corrosion products (uranium oxide and uranium hydride) and also by production of hydrogen gas, [2-6] through:

$$
\begin{gathered}
\mathrm{U}+2 \mathrm{H}_{2} \mathrm{O} \rightarrow \mathrm{UO}_{2}+2 \mathrm{H}_{2} \text { (Equation. 1) and } \\
2 \mathrm{U}+3 \mathrm{H}_{2} \rightarrow 2 \mathrm{UH}_{3} \text { (Equation. 2). }
\end{gathered}
$$

Where $\mathrm{H}_{2}$ can be derived from corrosion of uranium and other reactive metals in the waste form. This is a proven concern as previous incidents from other facilities have been documented, albeit using different storage conditions [7-8]. Uranium hydride $\left(\mathrm{UH}_{3}\right)$ is of particular interest as it has still not been definitely established whether conditions within the grout may be conducive to the formation and persistence of the compound. If this is true, determination of the rate at which the hydride forms

in the waste canister and knowledge of its subsequent persistence over time are important to understand. The second concern is the possible failure of the confining waste package during storage or transportation. The internal volume expansion caused by metals corroding in the grout could, if corrosion is significant, generate internal stresses sufficient to cause fracturing and cracking of the encasing grout and subsequently the steel drum, risking release of radioactive material into the 
surrounding environment [1]. Uranium hydride for example, occupies some 1.75 times the volume of the equivalent amount of uranium metal [9].

Quantifying the extent of uranium (and other metal) corrosion as a type of 'health check' is a major challenge when the waste is encapsulated in thick grout, itself contained within stainless steel drums. To date, all significant existing literature on uranium corrosion has been focused on its behaviour in unconfined environments, i.e. corrosion of bare metal [2-4, 10-13]. Studies of uranium corrosion in grout have found that attempts in air or a glove box to physically open the system and directly access the corrosion products can result in their vigorous exothermic chemical transformation [7]. The technical requirement is therefore to directly determine the corrosion state of uranium in the ILW but without breaking its physical confinement. The following work has demonstrated a solution to this problem by using high energy synchrotron x-rays to directly observe the corrosion state of groutencapsulated uranium, offering detailed in-situ observation and analysis of the arising products, without physically intervening and disrupting the system.

\subsection{Experimental Methods}

\subsection{Starting Materials}

The uranium used in the present work was taken as a metal coupon from an unirradiated Magnox fuel rod. The coupons were mechanically polished simultaneously using sequentially finer grades of abrasive SiC-paper down to a p2500 SiC grit finish and then cut into a series of sample sticks $20 \times 0.5$ $\mathrm{x} 0.5 \mathrm{~mm}$ in size. The sample size was selected to allow sufficient $\mathrm{x}$-ray penetration for analysis. Cut samples were pickled in $5 \mathrm{M} \mathrm{HNO}_{3}$ for 3 hours prior to grout-encapsulation to remove the surface oxide. Magnox uranium typically exhibits a high number density $\left(1430 \mathrm{~mm}^{-2}\right)$ of carbide inclusion particles on exposed surfaces (Figure 1) [14]. Prior analysis of the uranium using a focused ion beam (FIB) instrument showed that acid pickling had preferentially etched and removed inclusion particles exposed on the uranium surface (Figure1.). 
The samples were subsequently rinsed with water, and cleaned for five minutes in an ultrasonic bath with acetone and then methanol. After this procedure the samples had visibly tarnished, demonstrative of the formation of a thin oxide layer on the sample surface. This oxide was left to grow in air for a further 15 minutes prior to encapsulation to ensure that the oxide had reached the linear stage of growth and a complete coherent oxide had been formed, thereby ensuring that all subsequent reactions with the metal had to occur via this interface [12].

\subsection{Laboratory methods}

Three samples were analysed in total, all originating from the same Magnox uranium coupon. Two were immediately encapsulated in the most common grout formulation used in the UK nuclear industry: a 3:1 mixture of Blast Furnace Slag (BFS) and Ordinary Portland Cement (OPC) and prepared with 0.4 w/c. To examine the early stages of uranium corrosion in grout, both samples were then left to cure in a moist atmosphere for 3 days and then under atmospheric conditions for 1 week. Subsequently, one grouted sample was analysed at this reaction stage, whilst the other grouted sample was degassed under vacuum $\left(5 \times 10^{-4} \mathrm{mbar}\right)$ in a gas rig for 8 hours at $80^{\circ} \mathrm{C}$ and then heated for a further 16 hours at $170{ }^{\circ} \mathrm{C}$ to dry the grout before being exposed to a fixed volume of $\mathrm{H}_{2}$ at $600 \mathrm{mbar}$, still at $170{ }^{\circ} \mathrm{C}$. After a recorded $\mathrm{H}_{2}$ pressure drop equivalent to $0.012 \mathrm{mmol} \mathrm{H}_{2}$ uptake, $(\sim 3.5 \%$ of the total uranium mass transformed to uranium hydride), the reaction was halted by evacuating all $\mathrm{H}_{2}$ from the system and cooled under vacuum [12]. The hydriding conditions were selected based on previous work, to give a relatively short induction time and moderate growth rate. The remaining third sample was used as a bare (i.e. un-encapsulated) reference sample to compare both the oxidation and $\mathrm{H}_{2}$ corrosion behaviour due to 1) the encapsulation procedure and 2) the hydrogen exposure. This sample was analysed after the initial oxidation stage (1 week in air) and then again after exposure to $\mathrm{H}_{2}$ under nominally the same conditions as the grouted $\mathrm{H}_{2}$ corroded sample, with the exception of a longer reaction with $\mathrm{H}_{2}$ gas ( 0.038 mmol uptake, equivalent to $\sim 11.4 \%$ uranium hydride formation). 
All samples were analysed at the Joint Engineering, Environmental and Processing beam line (I12) at Diamond Light Source Limited, UK. The grout-encapsulated samples were measured by X-ray Tomography (XRT) and X-ray Powder Diffraction (XRPD) but the reference sample was only observed using radiography and XRPD due to time limitations.

\subsection{Synchrotron analysis}

The high resolution PCO pco.4000 imaging detector with its Module 4 camera was used for imaging using a monochromatic beam to obtain the best resolution possible for identifying uranium corrosion features, e.g. hydride spots $(1$ pixel $=0.98 \times 0.98 \mu \mathrm{m})$. Avizo ${ }^{\circledR}$ was used to produce $3 \mathrm{D}$ visualisations of the tomography.

For the purpose of data reduction, calibration of the detector and x-ray beam energy was determined from diffraction patterns recorded at multiple detector positions from a cerium dioxide $\left(\mathrm{CeO}_{2}\right)$ standard (NIST - Standard Reference Material 674b) [15]. The XRPD x-ray energy (114.08 keV) was lower than chosen for XRT $(115.97 \mathrm{keV})$ as the resolutions of the diffraction peaks determined to be better at this lower energy, and the XRT tomographs were clearer at the higher energy. 2D XRPD data were recorded using a flat panel Pixium RF4343 (Thales) in high resolution mode (2880 x 2881 pixels). This detector has a pixel size of 148 × $148 \mu \mathrm{m}$ and the beam size $\sim 340 \times 340 \mu \mathrm{m}$.

Data reduction was performed using in-house software. Where appropriate, background values were subtracted from the recorded diffraction patterns. In the two grout-encapsulated samples, the majority of the signal originated from the complex composition of the grout, hindering identification of uranium corrosion products. To overcome this, XRPD was performed in the grout region and averages of these patterns were chosen to act as the background for each diffraction pattern of interest, which was then subtracted from the main patterns for these samples. 


\subsection{Results}

Figures 2 and 3 show three dimensional reconstructions of the two grout-encapsulated samples, derived from the recorded XRT data. The X-ray transmission intensity is directly related to the density and atomic number of the material through which it is passing via $I=I_{0} e^{(-\mu / \rho) \rho l}$, where $I$ is the transmitted intensity of the beam, $I_{0}$ is the incident beam intensity, $\mu$ is the attenuation coefficient, $\rho$ is the density of the material, which together make $\mu / \rho$ the mass attenuation coefficient and $l$ the path length. Thus the greyscale of the radiograph is directly related to the density of the material being probed. The density of uranium is $19.1 \mathrm{gcm}^{-3}$, with the density of uranium hydride and oxide approximately half (10.95 $\mathrm{gcm}^{-3}$ and $10.97 \mathrm{gcm}^{-3}$ respectively) [9]. The technique can be used to show the spatial location of metal, corrosion product and grout with micro-scale precision. As uranium corrosion is the primary focus of this investigation, only the uranium and corrosion products have been presented in these figures. Due to limitations in the processing and reconstruction of the 2D tomographs, the exact densities of the individual materials could not be calculated. Instead the densities are compared relatively and the corrosion products were confirmed to be approximately half the greyscale of uranium, consistent with a $\mathrm{UH}_{3}$ or $\mathrm{UO}_{2}$ corrosion product.

The oxidised grout encapsulated sample was found to exhibit a relatively continuous layer of corrosion product across the surface of the metal, approximately $3 \mu \mathrm{m}$ thick, identified as uranium dioxide by XRPD (Figures 2 and 4(c).). By comparison, the oxide layer on the bare reference sample left in air was only $\sim 0.1 \mu \mathrm{m}$ thick, indicating significantly different corrosion rates over a one week period (Figures 2(c) and 4(a)). XRPD results for the reference and grout-encapsulated samples are presented in Figures 4(a) and (c) respectively. XRPD peak intensity data for the $\mathrm{UO}_{2}$ reflections corroborate the XRT derived observation that the encapsulated uranium had undergone a greater amount of surface corrosion.

The $\mathrm{H}_{2}$ corroded encapsulated sample recorded a considerably greater thickness and variation of corrosion product morphology relative to either of the air-oxidised samples (Figure 3.). Using the 
computational software Avizo ${ }^{\circledR}$ the total volume and distribution of consumed uranium could be calculated. For the latter sample $\sim 34 \%$ of the measured uranium volume had been transformed to $\mathrm{UH}_{3}$ and $\mathrm{UO}_{2}$. In comparison only $\sim 5 \%$ of the air exposed uranium encapsulated in grout had converted to $\mathrm{UO}_{2}$.

On the hydrided sample in grout, two morphologies of corrosion products were identified i) deep pits filled with blisters of flaky porous material that extended into the grout (Figure 3(b)); and ii) an enveloping layer blanketing the remaining surface of the metal. The dimensions of 12 identified pits were determined and the average thicknesses of the sites were $\sim 78 \mu \mathrm{m}$, with diameters as large as $\sim 300 \mu \mathrm{m}$. By comparison, the bare reference sample after $\mathrm{H}_{2}$ corrosion also showed a thick, flakey corrosion layer (Figure 5.). However, $\mathrm{UH}_{3}$ pitting sites were significantly less pronounced with postmortem ion beam analysis showing a more continuous $\mathrm{UH}_{3}$ layer across the surface $(\sim 20-50 \mu \mathrm{m}$ thick). This layer was presumed to have formed from coalescence of a population of isolated growth sites.

Figure 4 displays the average XRPD line scans results from all four samples. Unfortunately, the Pixium RF4343 detector had only micron scale resolution and therefore the nanometre scale thickness uranium oxide layer was not detected on either of the bare reference samples (Figures 4(a) and (b)). Instead this was identified through secondary ion mass spectrometry (not shown here). As expected, $\mathrm{UO}_{2}$ was the dominant corrosion product for the encapsulated air-exposed sample (Figure 4(c)) and $\mathrm{UH}_{3}$ for the $\mathrm{H}_{2}$ exposed samples, as well as additional phases previously observed on the air-oxidised samples (Figures 4(b) and (d)). The $\mathrm{H}_{2}$-corroded sample encapsulated in grout also showed strong indications (greater than of the encapsulated oxidised sample) of additional $\mathrm{UO}_{2}$ that was attributed to further oxidation by pore water vapour during the vacuum drying process prior to induced $\mathrm{H}_{2}$ corrosion.

The relative lattice strain of the uranium in each sample was measured using the Williamson and Hall method, which incorporates both the crystallite size and overall lattice strain into the breadth of the 
measured peaks [16]. The XRPD patterns were averaged for each sample to reduce error and a Gaussian peak shape function was applied to the recorded (111), (022), (112) and (131) diffraction peaks of uranium for all three samples. It was observed that the recorded lattice strain (\%) was least in the bare reference sample, measuring 3.31, increased in the grout-encapsulated sample (3.53) and, on through to the $\mathrm{H}_{2}$-corroded reference sample (3.73) and finally the $\mathrm{H}_{2}$ corroded encapsulated sample (4.15). This result strongly correlates with the increasing volumes of corrosion product determined on the uranium samples. In addition, the $\mathrm{UH}_{3}$ detected on the grout encapsulated sample exhibited elevated compressive strain (5.89) relative to that on the corresponding reference sample, 3.27. This difference was attributed to the mechanical confinement imposed by the enveloping grout body, approximately 13.8-27.6 MPa compressive strength [17].

\subsection{Discussion}

The physical structure of the corrosion products arising on a metal surface can be an effective indicator of the type of corrosion product that has formed. It can also express the stage, extent and sometimes the conditions of growth. Here, XRT has been used to show the corrosion morphology and XRPD to determine the crystal structure and identity of the generated products. When combined, this information provides important evidence to diagnose the corrosion evolution of a waste-form containing uranium in contact with grout. With periodic measurements, it can enable determination of reaction rates, mechanisms and the evolving density and distribution of the arising corrosion products. Oxide formation on bare uranium metal, no matter what the gas species (air or water vapour), initially grows very rapidly to form a layer approximately $20-30 \mathrm{~nm}$ thick [18-20]. After this, the growth rate slows parabolically eventually resulting in a stable linear reaction rate, as the transport of oxygen species through the oxide layer is limited by the thickness of the oxide layer. This rate is dependent on the reaction environment and material properties [10, 21]. As the oxides described in these samples are greater than $20-30 \mathrm{~nm}$ thick, the reaction kinetics are assumed to be in this linear regime. 
For the experiments reported here, despite having undergone the same preparation procedure (submersion in $\mathrm{HNO}_{3}$ for 3 hours and oxidised in air for one week), the air-exposed and groutencapsulated uranium sample showed significantly greater oxidation in comparison to the bare airexposed reference sample; oxide thicknesses were $3 \mu \mathrm{m}$ versus $0.1 \mu \mathrm{m}$ respectively. Figure 6 provides a comparison of the uranium oxidation rates measured in these samples (assuming linear rate kinetics) against those presented in the comprehensive review by Haschke for air and water vapour [12]. In this review, empirical equations (plotted in Figure 6) have been formulated for specific uranium oxidation systems at different temperatures and conditions: for the $\mathrm{U}+\mathrm{O}_{2}$ system below $200^{\circ} \mathrm{C}$ the $\ln \mathrm{R}=6.19$ - $(8077 / \mathrm{T})$ equation was followed and the equations $\ln \mathrm{R}=10.64-(7725 / \mathrm{T})$ and $\ln \mathrm{R}=8.33-$ $(6860 / \mathrm{T})$ were used for below $100{ }^{\circ} \mathrm{C}$ and between $100-200{ }^{\circ} \mathrm{C}$ respectively for the $\mathrm{U}+\mathrm{H}_{2} \mathrm{O}$ system. In these equations $\mathrm{T}$ is temperature. Oxide thicknesses obtained from tomographic and FIB measurements of the air-exposed and hydrided samples were converted to rates via $\mathrm{R}=\mathrm{g} \mathrm{U} /\left(\mathrm{cm}^{2} \mathrm{~min}\right)$ to compare against the empirical equations. Oxygen is believed to suppress the $\mathrm{U}$ $+\mathrm{H}_{2} \mathrm{O}$ reaction rate at $\mathrm{T}<35^{\circ} \mathrm{C}$, and hence both of these samples should be initially compared to rate models of the $\mathrm{U}+\mathrm{O}_{2}$ system $[12,22]$. The comparison shows that the bare reference sample was determined to have oxidised at a rate an order of magnitude faster than the predicted $\mathrm{U}+\mathrm{O}_{2}$ reaction. This is ascribed to the initial parabolic oxidation rate being unaccounted for in the linear rates and also accelerated oxidation attributable to the preparatory nitric acid treatment [12]. It should be noted that in a system where the supply of oxidants is constantly replenished, it is generally accepted that uranium corrosion will progress until the metal is fully consumed.

Similarly, the oxidised sample encapsulated in grout was determined to have oxidised at rates three orders of magnitude faster than predicted for air corrosion, a rate comparable with an anoxic $\mathrm{U}+\mathrm{H}_{2} \mathrm{O}$ corrosion regime. This is not unexpected and is ascribed to reaction with water trapped in isolated pores, present in the grout during and after curing, which would have quickly become anoxic. To confirm if the pore waters contacting the grout were likely to be anoxic, the alkalinity and redox state 
were measured on a further grouted sample. This sample was similarly prepared but was submersed in $40 \mathrm{ml}$ of water for 1.5 weeks and the $\mathrm{pH}$, oxygen level and redox potential were measured in semisealed conditions. As expected, the $\mathrm{pH}$ rose to 12.32 , oxygen became strongly depleted $\left(1.87 \mathrm{mgL}^{-1}\right)$ and negative redox $-222.3 \mathrm{mV}$ was established. A pure grout sample was also measured showing similar $\mathrm{pH}$ levels but ordinary atmospheric oxygen and redox levels. The initial oxidation of uranium must therefore be responsible for depleting the levels of water dissolved oxygen within the grout pores, leading later to more rapid anoxic aqueous corrosion.

For the encapsulated and hydrided sample, the oxide layer is thicker still due to the pre-hydriding vacuum-drying process. However, the measured oxidation rate was an order of magnitude slower than the empirically derived rate and this was ascribed to the finite and decreasing sources of water in the vacuum system during degassing; i.e. the accelerated oxidation reaction was only expected to have occurred for a brief period, and not the full period of heating. The $\mathrm{H}_{2} \mathrm{O}$ corrosion reaction is well reported to form stoichiometric oxide, $\mathrm{UO}_{2.00}$, in agreement with the XRPD data measured for all samples (Figure 4) [10, 21].

These findings are significant for ILW packaging. The oxidised sample encapsulated in grout has shown accelerated oxidation ascribed to the establishment of an anoxic aqueous corrosion regime following rapid initial depletion of pore-water oxygen and thereafter following the relatively rapid $\mathrm{U}+2 \mathrm{H}_{2} \mathrm{O} \rightarrow \mathrm{UO}_{2}+2 \mathrm{H}_{2}$ (Equation 1) reaction. The water/cement ratio and ratio of OPC to BFS used in ILW, and hence for this experiment, were chosen partly because of the low gas and water permeability of the resulting pore structure [23-24]. Since ILW can be warm during encapsulation due to exothermic reactions associated with cement curing $\left(>80{ }^{\circ} \mathrm{C}\right)$, the short term corrosion reaction expressed in Equation 1 would be expected to accelerate further in full size ILW packages. Escape of evaporated water and oxygen ingress from the air will be slow through the low permeability grout, especially as the grout is confined by stainless steel in an ILW drum; thus it is unlikely to hinder Equation 1. These results suggest potential for hydrogen generation - a flammable gas and precursor 
to uranium hydride formation - by corrosion of uranium and other reactive metals in grouted ILW and its accumulation in the waste packages [1]. Nevertheless, assuming gas diffusion is slow and no additional water is added to the system, Equation 1 may be limited by the finite source of water existing within the grout body. Therefore hydrogen generation and possible $\mathrm{UH}_{3}$ formation may initiate rapidly but then cease upon depletion of the reactants.

In contrast to uranium oxide formation which occurs relatively uniformly across a metal surface, corrosion by hydrogen is localised, occurring in a spot-wise initial distribution [25]. The progressive stages of uranium hydriding have been previously discussed in a detailed review by Bloch and Mintz [26]. Ultimately, total conversion of uranium to uranium hydride will occur if there is a sufficient supply of hydrogen. Hydriding behaviour (induction period, rate of hydride growth and morphology of the initial hydride sites) is observed to be influenced by the conditions of growth and features present on the surface of the uranium [3, 11, 25-27].

In this current study, the corrosion product morphology observed on the $\mathrm{H}_{2}$-reacted grouted sample is characteristic of spot-wise hydride formation. On the uranium surface measured $\left(\sim 3.7 \mathrm{~mm}^{2}\right), 64$ established $\mathrm{UH}_{3}$ sites were identified, giving a surface density of $13.3 \mathrm{UH}_{3}$ sites.mm ${ }^{-2}$. This value is taken as conservative, as smaller developing and more laterally-extensive sites may be present that cannot be detected by the resolution of XRT. The examined $\mathrm{UH}_{3}$ pits exhibited significant variation in diameter and depth, with a maximum depth of $130 \mu \mathrm{m}$, but averaging $78 \mu \mathrm{m}$. Assuming that each individual $\mathrm{UH}_{3}$ formation site grew at the same rate, this observation suggests that the induction period to hydride formation varied across the surface causing some sites to form before others. In previous hydriding studies of bare uranium, the observed variation in the dimensions of hydride growths is significantly less than shown here (as seen in the $\mathrm{H}_{2}$-corroded reference sample), [26] indicating that the enveloping grout provides a heterogeneous barrier to the accumulation of hydrogen at the uranium surface. In the hydrided grouted sample the layer of corrosion product between the 
$\mathrm{UH}_{3}$ growth centres was ascribed to uranium oxide that was assumed to have formed before the hydride formation was induced (Equation 1).

\subsection{Conclusions}

The present investigation has shown that synchrotron XRT and XRPD may be used to successfully observe the evolution of corrosion products of uranium samples encapsulated in grout. The study shows that you can accurately distinguish uranium metal from its associated corrosion products insitu, without the need for breaking the grout confinement and providing high spatial resolution reconstructions of sample volumes and geometries, as well as coincident diffraction analysis for phase identification. The surrounding mass of grout was not found to exert any significant suppression on the hydride forming reaction, but conversely it was found to encourage hydride growth in selective isolated spots compared to a more uniform hydride rate across a bare uranium surface. Combined with laboratory studies and existing literature on uranium corrosion, this experiment, as expected, has confirmed that encapsulating uranium in grout will encourage initial accelerated growth of uranium dioxide via the anoxic $\mathrm{U}+\mathrm{H}_{2} \mathrm{O}$ reaction, promoting strain in the uranium through an rapidly developing corrosion layer. This study has also demonstrated the successful use of XRT and XRPD for non-invasive analysis of pyrophoric and ultra-dense materials.

Further work will seek to scale up this imaging capability by moving to the use of gamma-rays in preference to x-rays and achieve transmission through much larger samples. Ultimately the objective is to rapidly scan full sized waste drums achieving micron-scale resolution of the entrapped metals and associated corrosion products. In the meantime, the aim is to accumulate enough fundamental data from carefully conceived small experiments to improve our predictive capability in identifying and correctly managing problematic waste drums.

\section{Acknowledgements}


The authors would like to thank Diamond Light Source for access to beamline I12 (EE9127-1) that contributed to the results presented here. Also to the beam line staff, Michael Drakopoulos, Christina Reinhard, Robert Atwood, Thomas Connolley and Nghia Vo for their help. This work was funded by EPSRC and the UK Nuclear Decommissioning Authority's Radioactive Waste Management Directorate (NDA RWMD) under the GEOWASTE program. Since April 2014, the RWMD has become a wholly-owned subsidiary of the NDA, Radioactive Waste Management Limited (RWM).

\section{References}

[1] G. A. Fairhall and J. D. Palmer, The Encapsulation of Magnox Swarf in Grout in the United Kingdom, Cem. Concr. Res. 22 (1992) 293-298.

[2] F. Le Guyadec, X. Genin, J. P. Bayle, O. Dugne, A. Duhart-Barone and C. Ablitzer, Pyrophoric behaviour of uranium hydride and uranium powder, J. Nucl. Mater. 396 (2010) 294-302.

[3] R. A. Owen and L. W. Scudamore, A microscope study of the initiation of the hydrogen-uranium reaction. Corros. Sci. 6 (1966) 461-466.

[4] R. J. McEachern and P.J Taylor, J. A review of the oxidation of uranium dioxide at temperatures below $400^{\circ} \mathrm{C}$, J. Nucl. Mater. 254 (1998) 87-121.

[5] J. Belle, Uranium dioxide: Properties and nuclear applications, Naval Reactors, Division of Reactor Development. U. S. Atomic Energy Commission: Washington 1961. http://catalog.hathitrust.org/Record/001112664, accessed on $19^{\text {th }}$ May 2014.

[6] J. S. Anderson, E. A. Harper, S. Moorbath, L. E. J. Roberts, The properties and microstructure of uranium dioxide: Their dependence upon the mode of preparation. Atomic Energy Research Establishment: 886 of AERE report / C R: AERE report (1957).

[7] T.C. Totemeier, Characterization of uranium corrosion products involved in a uranium hydride pyrophoric event, J. Nucl. Mater. 278 (2000) 301-311. 
[8] D. H. Wood, S. A. Snowden, H. J. Howe, L. L. Thomas, D. W. Moon, H. R. Gregg and P.E. Miller, Regarding the chemistry of metallic uranium stored in steel drums, J. Nucl. Mater. 209 (1994) 113-115.

[9] R. E. Rundle, N. C. Baenziger, A. S. Wilson and R. A. McDonald, The structures of the carbides, nitrides and oxides of uranium, J. Am. Chem. Soc. 70 (1948) 99-105.

[10] C. A. Colmenares, Oxidation mechanisms and catalytic properties of the actinides, Prog. Solid State Chem. 15 (1984) 257-364.

[11] S. G. Bazley, J. R. Petherbridge and J. Glascott, The influence of hydrogen pressure and reaction temperature on the initiation of uranium hydride sites, Solid State Ionics. 211 (2012) 1-4.

[12] J. M. Haschke, Corrosion of uranium in air and water vapor: consequences for environmental dispersal, J. Alloys Compd. 278 (1998) 149-160.

[13] T. B. Scott, G. C. Allen, I. Findlay, and J. Glascott, $\mathrm{UD}_{3}$ formation on uranium: evidence for grain boundary precipitation, Philos. Mag. 87 (2007) 177-187.

[14] E. H. P. Cordfunke, Investigations on uranium carbonitrides (i): The lattice parameters of the solid solutions, J. Nucl. Mater. 56 (1975) 319-326.

[15] M. L. Hart, M. Drakopoulos, C. Reinhard, and T. Connolley, Complete Elliptical Ring Geometry Provides Energy and Instrument Calibration for Synchrotron-based Two-dimensional X-ray Diffraction, J. Appl. Crystallogr. 46 (2013) 1249-1260.

[16] G. K. Williamson and W. H. Hall, X-ray line broadening from filed aluminium and wolfram, Acta Metall. 1 (1953) 22-31.

[17] K. M. Khan, and U. Ghani, Effect of blending of Portland grout with ground granulated blast furnace slag on the properties of grout, $26^{\text {th }}$ Our World in Grout and Structures. 100029040: 2004

[18] R. M. Harker, The influence of oxide thickness on the early stages of the massive uraniumhydrogen reaction, J. Alloys Compd. 426 (2006) 106-117.

[19] J. G. Schnizlein, P. J. Pizzolato, H. A. Porte, J. D. Bingle, D. F. Fischer, L. W. Mishler and R. C. 
Vogel, Ignition behaviour and kinetics of oxidation of the reactor metals, uranium, zirconium, plutonium and thorium, and binary alloys of each, A US DOE Report ANL-5974, Argonne National Laboratory: Lemont, IL 1959.

[20] L. Leibowitz, J. G. Schnizlein, L. W. Mishler and R. C. Vogel, The Kinetics of Oxidation of Uranium between $125^{\circ}$ and $250^{\circ} \mathrm{C}$, J. Electrochem. Soc. 108 (1961) 1153-1155.

[21] G. C. Allen, P. M. Tucker and R. A. Lewis, X-ray photoelectron-spectroscopy study of the initial oxidation of uranium metal in oxygen + water-vapour mixtures, J. Chem. Soc. Faraday Trans. 2. 80 (1984) 991-1000.

[22] G. W. McGillivray, D. A. Geeson, and R. C. Greenwood, Studies of the kinetics and mechanism of the oxidation of uranium by dry and moist air a model for determining the oxidation rate over a wide range of temperatures and water vapour pressures, J. Nucl. Mater. 208 (1994) 81-97.

[23] J. E. Slater, J. R. Schroeder, K. A. Greene, R. Horstman, H. M. Hoersh, H. P. Mahy and A. S. Kleinberg, Corrosion of metals in association with concrete, ASTM STP 818, ASTM International (1983)

[24] D. E. Moore, C. A. Morrow and J. D. Byerlee, Use of swelling clays to reduce permeability and its potential application to nuclear waste repository sealing, Geophys. Res. Lett. 9 (1982) 1009-1012.

[25] C. P. Jones, T. B. Scott, J. R. Petherbridge, and J. A. Glascott, A surface science study of the initial stages of hydrogen corrosion on uranium metal and the role played by grain microstructure, Solid State Ionics. 231 (2013) 81-86.

[26] J. Bloch, and M. H. Mintz, Kinetics and mechanisms of metal hydride formation review, J. Alloys Compd. 253-254 (1997) 529-541.

[27] R. Arkush, Site related nucleation and growth of hydrides on uranium surfaces, J. Alloys Compd. 244 (1996) 197-205. 


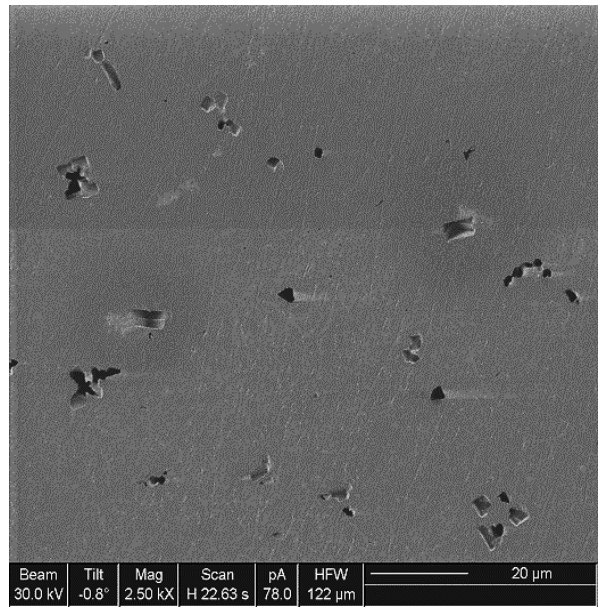

Figure. 1. (a) Secondary electron image of a typical nitric acid treated surface. Inclusions shown here as dark points protruding from the metal surface, are mono carbides of uranium (UC).

(a)

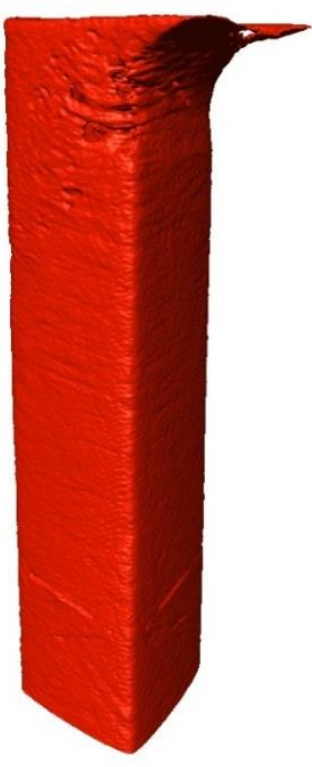

(b)

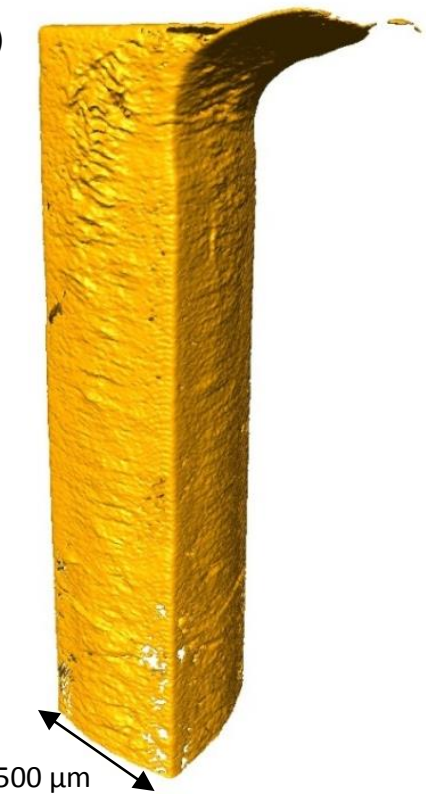

(c)

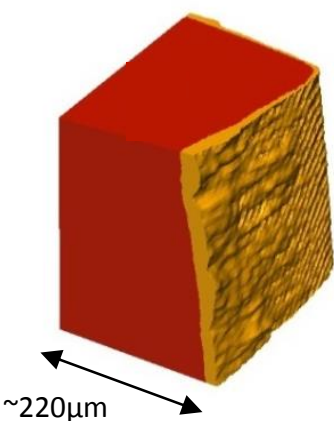

(d)

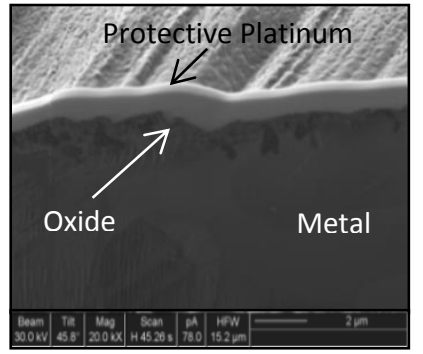

19.1

Density $\left(\mathrm{g} \mathrm{cm}^{-3}\right)$

10.97

$U$

$\mathrm{UO}_{2}$

Figure 2. Relative density maps of the oxidised grout-encapsulated sample. (a) shows the inner uranium and (b) the corrosion layer. (c) is a cross-section from a segment of a combined (a) + (b) image. (d) Presents a focused ion beam image cross-section of the bare reference sample. 
(a)

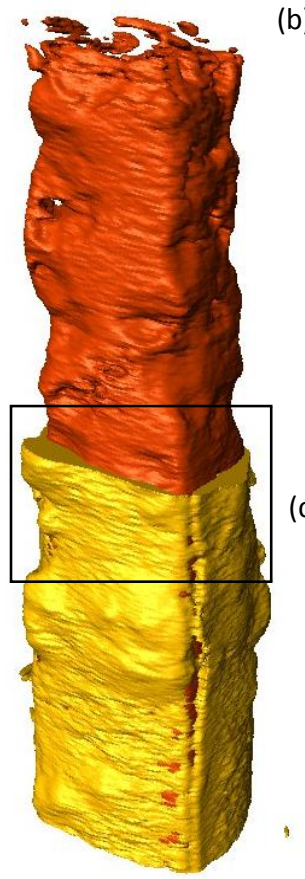

(b) (i)
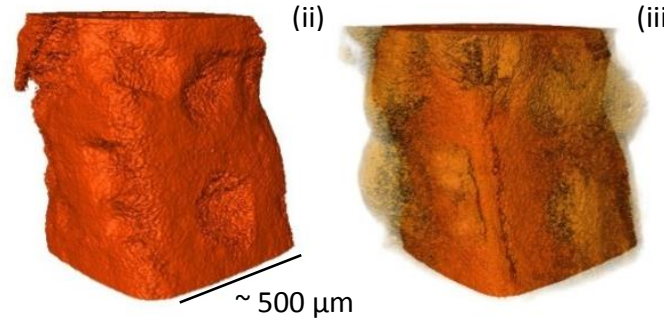

(iii)
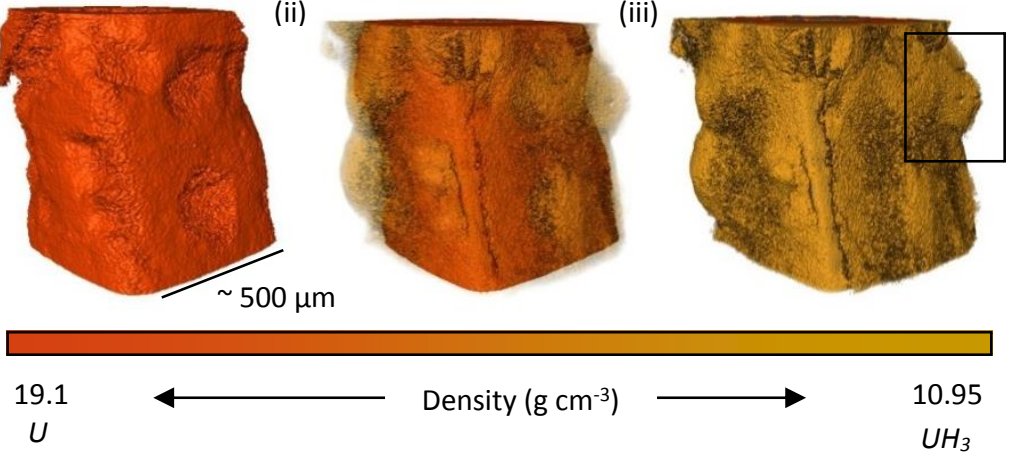

(c)

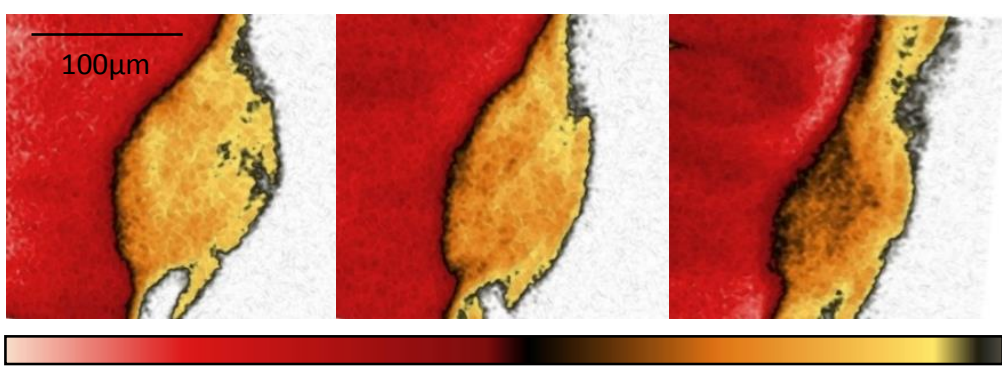

19.1

Density $\left(\mathrm{g} \mathrm{cm}^{-3}\right)$

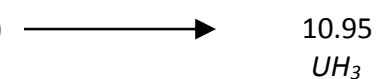

Figure 3. 3D reconstructions of the $\mathrm{H}_{2}$-corroded uranium encapsulated in grout. (a) Represents the entirety of the uranium rod examined showing both the inner original uranium (orange) and a mixture of $\mathrm{UO}_{2}$ and $\mathrm{UH}_{3}$ in yellow. The box drawn on (a) corresponds to the area examined in (b). (b) and (c) are relative density maps of the uranium and corrosion products in aspect and cross-section respectively. In (c), black is used to aid distinction between corrosion products, uranium and grout, with the area corresponding to the box drawn on (biii). 

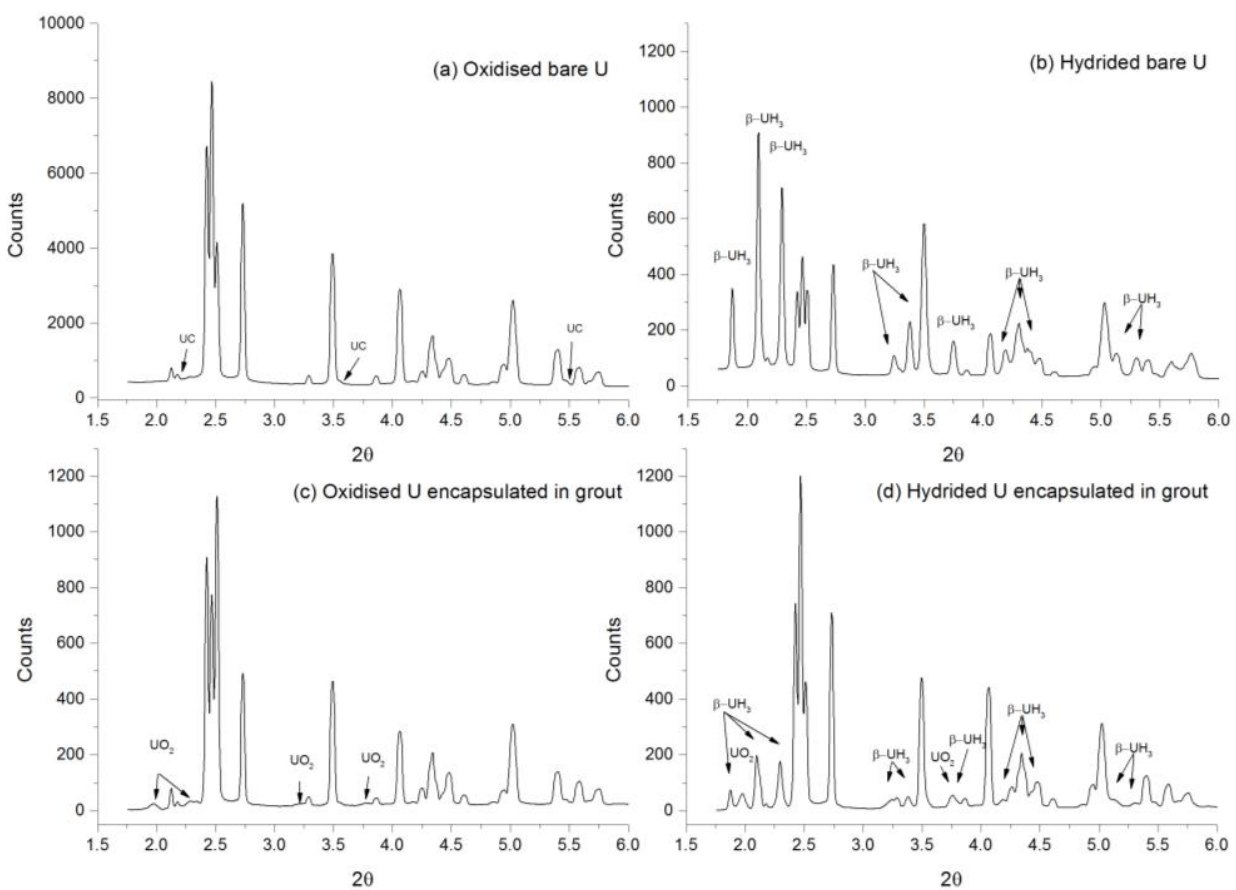

Figure 4. Averaged XRPD data for all four samples. (a) and (b) show the bare reference sample before and after exposure to $\mathrm{H}_{2}$ respectively. (c) and (d) display the oxidised and hydrided uranium encapsulated in grout. All unlabelled peaks are identified as $\alpha-U$.

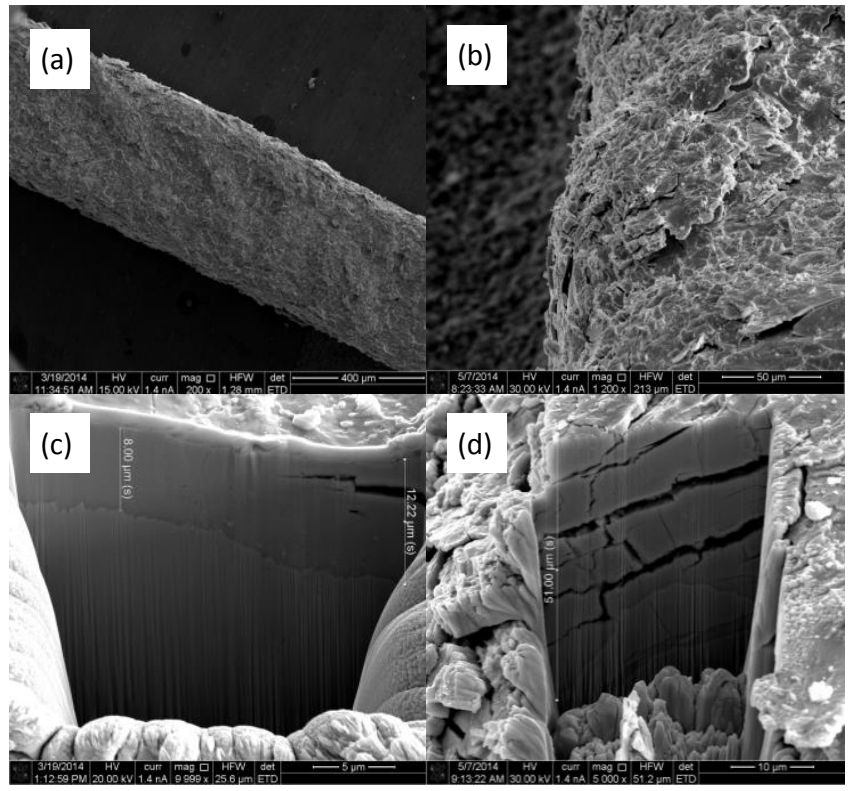

Figure 5. Secondary electron images of the bare reference sample after exposure to $\mathrm{H}_{2}$. (a) and (b) are low magnification images. (c) and (d) are images of FIB sections of the hydride layer across the surface of the metal. 


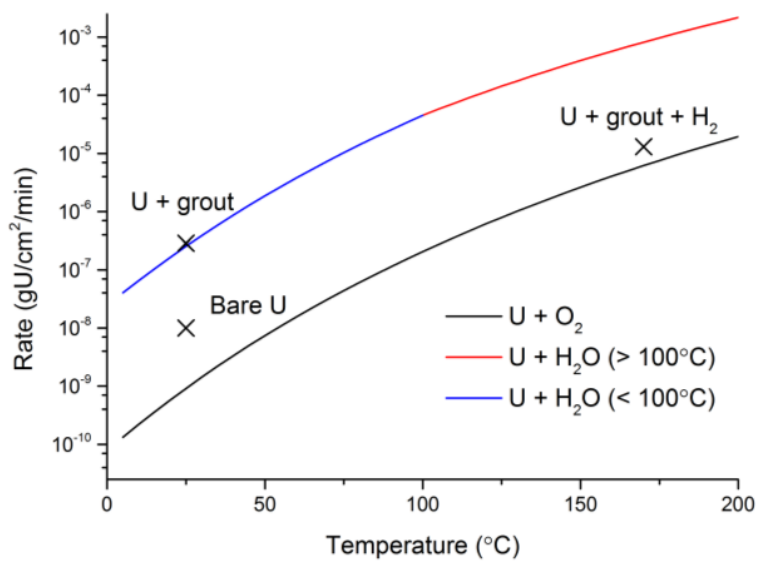

Figure 6. A comparison of the measured oxidation rates $(\mathrm{R})$ to the equation models provided by Hascke [12]. 
